\title{
Finite Element Modeling for Prediction the Effect of Nose Radius on Cutting Forces for Titanium (Ti-6Al-4V) Alloy
}

\author{
M. H. Ali ${ }^{1, *}$, B. Mohamed ${ }^{1}$, M.N.M. Ansari ${ }^{1}$ and B. A. Khidhir ${ }^{2}$ \\ ${ }^{1}$ Dpt. of Mechanical Engineering, Universiti Tenaga Nasional Putra Jaya, Malaysia. \\ ${ }^{2}$ Dpt of Mechanical Engineering, Sulaimanyah Technical College, Iraq.
}

Received 4 May 2012; Accepted 17 September 2012

\begin{abstract}
This paper presents a study the effect of nose radius $\left(R_{z}-\mathrm{mm}\right)$ on the cutting forces during the machining process in a face milling operation for titanium (Ti-6Al-4V) alloy. To improve the prediction of the effect of nose radius $\left(R_{z}\right.$-mm) on cutting force components so the cutting tests were performed with various nose radiuses $\left(R_{z}-\mathrm{mm}\right)$ while the depth of cut $\left(d\right.$-mm), feed rate $(f-\mathrm{mm} /$ tooth $)$ and cutting speed $\left(v_{c} \mathrm{~m} / \mathrm{min}\right)$ were remained constant. The main cutting force $\left(F_{c}\right)$ and feed cutting force $\left(F_{t}\right)$ were measured by using the ABAQUS/EXPLICIT software simulation through the development a two-dimensional orthogonal cutting process of finite-element modeling. The results led to the conclusion that the nose radius $\left(R_{z}-\mathrm{mm}\right)$ has affected directly on the cutting force components. An increase in the nose radius $\left(R_{z}-\mathrm{mm}\right)$ led to more convergence in terms of behavior between the main cutting force $\left(F_{c}\right)$ and feed cutting force $\left(F_{t}\right)$ and its direct effect on the quality and quantity of product.
\end{abstract}

Keywords: Finite Element Modeling (FEM), Nose Radius, Cutting Forces, Titanium (Ti-6Al-4V) Alloy.

\section{Introduction}

Titanium alloy [1] is catchy material due to their unique high strength-weight ratio that is maintained at their exceptional corrosion resistance and elevated temperatures. The main application of titanium alloy is found in the aerospace industry that it is used in both engine components and airframes. There is non-aerospace application can take advantage mainly of corrosion resistance and their excellent strength properties $[2,3,4]$. These reasons led to become that titanium (Ti-6Al-4V) alloy is known as difficult machining materials.

Researchers are focusing to use a wide range of tools and techniques to ensure that the designs they are created it saves. Probably, sometimes accidents could happen while they work in the laboratories or factories. Industries need to know whether a product failed or how many percentage need to success it. That is because the design was inadequate. Nevertheless, they have to ensure that the product works well under a wide range of conditions and try to avoid from failure due to any cause. In this regard, finite element modeling (FEM) could help to avoid the failure and improve the success.

FEM is a very important tool for machining application analysis because it can produce very accurate and significant for results. In general modeling the plastic material flow, there are two basic approaches to assigning elements [5].

*E-mail address: muezhm@hotmail.com

ISSN: 1791-2377 @ 2012 Kavala Institute of Technology. All rights reserved.
Firstly, fixing the elements in space and allowing the material to flow through them (Eulerian technique) and secondly, dividing the material into elements that move with the flow (Lagrangian technique). Therefore, the JohnsonCook constitutive model of titanium (Ti-6Al-4V) alloy had been established and developed.

The cutting process of titanium (Ti-6Al-4V) alloy was simulated using the orthogonal cutting finite element model. However, in the simulation system, the Johnson-Cook model considered the adiabatic effect is more accurately [6].

The main objective of this present paper is predicting the effect of nose radius $\left(R_{z}-\mathrm{mm}\right)$ on the cutting force components during the machining process for titanium (Ti$6 \mathrm{Al}-4 \mathrm{~V})$ alloy through a face-milling operation by using finite element modeling (FEM).

\section{Finite Element Modeling (FEM)}

The finite element modeling (FEM) was calculated the cutting forces, stress and strain, temperatures or other desired unknown parameters in the finite element model. Therefore, a commercial finite-element ABAQUS/EXPLICIT software system requires the following information procedures:

1. Material and tool modeling

2. Contact and failure laws analysis

3. Meshing elements and assembly parts 


\subsection{Work-piece Material And Tool Modeling}

The two-dimensional orthogonal development of the cutting process is considered fully thermo-mechanically coupled implicit [7]. This work-piece material and tool geometry are designed by using finite element modeling (FEM). The work-piece is modeled of $50 \mathrm{~mm} \times 100 \mathrm{~mm}$ with machining parameters; cutting depth $(d-\mathrm{mm})$, feed rate $(f-\mathrm{mm} /$ tooth $)$ and cutting speed $\left(v_{c}-\mathrm{m} / \mathrm{min}\right)$ as shown in Table 1.

Furthermore, the tool is modeled with the assumption that it is mechanically rigid. To design the cutting tool geometry was selected rake angle and clearance angle used as shown in Table 1. Thermo-physical material properties were used for the cemented carbide inserts. The cutting of the tool geometry is shown in Fig. 1.

\subsection{Contact and Failure Laws Analysis}

The parameters have been verified with the simulation results. In addition, the failure parameters $d 1$ to $\mathrm{d} 5$ are acquired from R. Lesuer [8]. Where: $d 1=-0.09, d 2=0.25$, $d 3=-0.5, d 4=0.014$, and $d 5=3.87$. In this present paper, titanium (Ti-6Al-4V) alloy is modeled with the JohnsonCook plasticity model of Eq. 1. Besides that, the material failure strain $\varepsilon_{f}$ is detailed in Eq. 2, as below:

$$
\begin{aligned}
& \sigma=\left(A+B \varepsilon_{p}{ }^{n}\right)\left(1+C \ln \left(\varepsilon / \varepsilon_{0}\right)\right)\left(1-(T-T r / T m-T r)^{\wedge} m\right) \\
& \varepsilon_{f}=(d 1+d 2 \operatorname{ed} 3(\sigma p / \sigma e))\left(1+d 4 \ln \left(\varepsilon p / \varepsilon_{0}\right)\right) *(1+d 5((T- \\
& T r) /(T m-T r)))
\end{aligned}
$$

where: $\sigma$ is flow stress, $\varepsilon_{p}$ and $\varepsilon$ are strain and strain rate, $\varepsilon_{0}$ is the reference strain rate $(1 / s)$ and $n, m, A, B$ and $C$ are constant parameters for Johnson-Cook material model as shown in Table 2. $\varepsilon_{p} / \varepsilon_{0}$ as a function of non-dimensional plastic strain, a dimensionless deviatoric-pressure stress ratio $\sigma p / \sigma e$ (where $\sigma p$ is the pressure stress and $\sigma e$ is the (VonMises stress)), computed or modeled work-piece temperature $(T)$, room temperature $(\mathrm{Tr})$, and melting temperature $(\mathrm{Tm})$ [9].

\subsection{Meshing Elements and Assembly Parts}

From Fig. 1 and Fig. 2, the mesh generator starts by creating elements along the boundary of the work-piece material and the cutting of tool geometry. The meshing elements and assembly parts between work-piece material and tool geometry were created at the contact surface between the cutting of tool edge and work-piece of titanium (Ti-6Al-4V) alloy as shown in Fig. 2. The total number of elements is used with approximately about 1089 and the number of nodes is 1169 .

Table 1. Cutting Parameters Modeling.

\section{Cutting Parameters}

$\begin{array}{ccccc}\begin{array}{c}\text { Rake angle, } \\ \gamma(\mathrm{deg})\end{array} & \begin{array}{c}\text { Clearance } \\ \text { angle, } \alpha \\ (\mathrm{deg})\end{array} & \begin{array}{c}\text { Depth of } \\ \text { cut, } d(\mathrm{~mm})\end{array} & \begin{array}{c}\text { Cutting } \\ \text { speed, } v_{c} \\ (\mathrm{~m} / \mathrm{min})\end{array} & \begin{array}{c}\text { Feed rate, } f \\ (\mathrm{~mm} / \mathrm{tooth})\end{array}\end{array}$

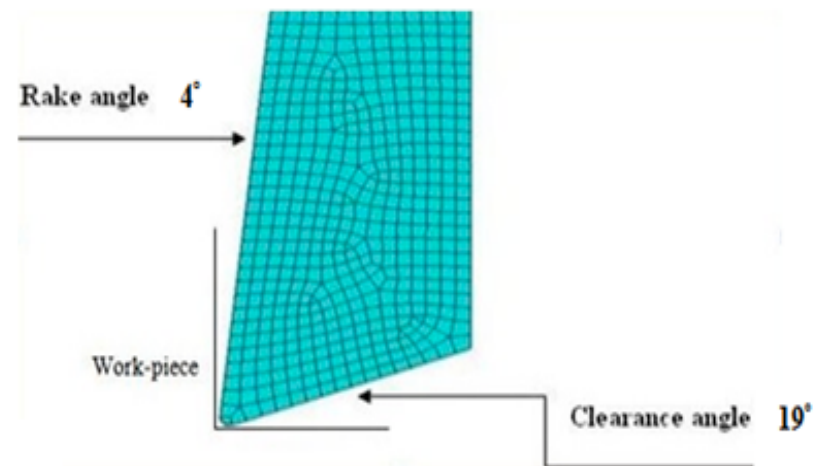

Fig.1 Cutting Tool Geometry.

Table 2. Constant Parameters for Johnson-Cook Material Model of Titanium (Ti-6Al-4V) Alloy [10].

\begin{tabular}{cc}
\hline Cutting constant & Values \\
\hline$A(\mathrm{MPa})$ & 987.8 \\
$B(\mathrm{MPa})$ & 761.5 \\
$n$ & 0.41433 \\
$m$ & 1.516 \\
$C$ & 0.01516 \\
Reference strain rate & 2000 \\
Young's modulus $(\mathrm{GPa})$ & 113.8 \\
Poisson's Ratio & 0.342 \\
Melting Temp. ${ }^{\circ} \mathrm{C}$ & 1605 \\
Density $\left(\mathrm{kg} / \mathrm{m}^{3}\right)$ & 4428 \\
\hline
\end{tabular}

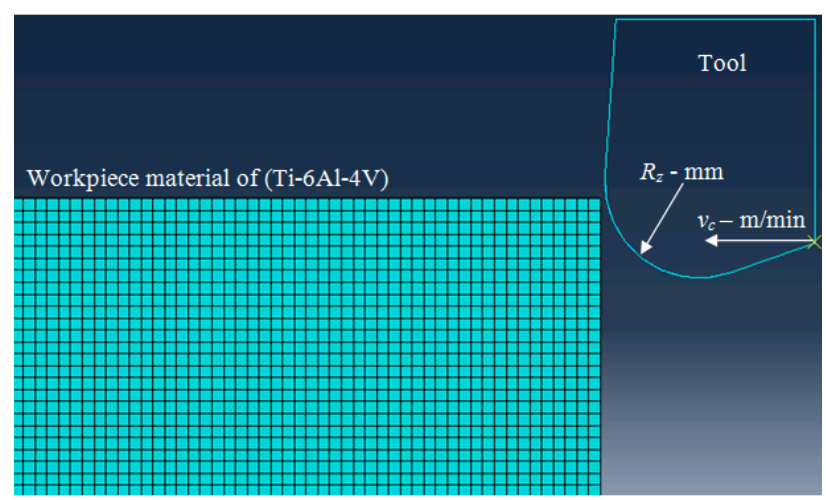

Fig. 2. Meshing Elements and Assembly Parts Between Work-piece and Tool.

\section{Results Analysis}

The finite element modeling (FEM) was measured two different points for each of the cutting force components such as main cutting force $\left(F_{c}\right)$ and feed cutting force $\left(F_{t}\right)$ when various nose radiuses $\left(R_{z}-\mathrm{mm}\right)$. The machining test number was designed by three experiments tests that start from $\mathrm{T} 1$ at $0.8 \mathrm{~mm}, \mathrm{~T} 2$ at $1.2 \mathrm{~mm}$, and $\mathrm{T} 3$ at $1.6 \mathrm{~mm}$ as shown in Table 3.

\section{Discussion}

The nose radius $\left(\mathrm{R}_{\mathrm{z}}-\mathrm{mm}\right)$ has affected on the main cutting force $\left(F_{c}\right)$ according to the experimental tests measured in two different points. The result tests obtained from $\mathrm{T} 1$ and 
T2 that the behavior of main cutting force $\left(F_{c}\right)$ was decreased from point 1 to point 2 with distinction their values of down sharply as shown in Fig. 3 and Fig. 4. However, T3 shown that the main cutting force $\left(F_{c}\right)$ was increased with converged their values as shown in Fig. 5. On the other hand, the result test shows that the nose radius $\left(R_{z^{-}}\right.$ $\mathrm{mm}$ ) has affected on the feed cutting force $\left(F_{t}\right)$ but a different behavior and effect. From T1 and T3 found that the feed cutting force $\left(F_{t}\right)$ was increased from point 1 to point 2 with characteristic their values of a rise sharply. Although, test number (T2) obtained that the feed cutting force $\left(F_{t}\right)$ was decreased their values from points 1 to point 2 during cutting process. These experiments have shown that the main cutting force $\left(F_{c}\right)$ and feed cutting force $\left(F_{t}\right)$ have similar behavior at T2 they showed a decrease and at T3 have shown increases. This is because the nose radius $\left(R_{z}-\mathrm{mm}\right)$ has affected on machining parameters such as cutting force components. Therefore, an increase in the nose radius $\left(R_{z}-\mathrm{mm}\right)$ led to more convergence in terms of behavior between the main cutting force and feed cutting force. For instance, the test number (T3) at $R_{z}=1.6 \mathrm{~mm}$ the main cutting force was increased from a point $1=1760753 \mathrm{~N}$ to point $2=177.723 \mathrm{~N}$. Then, the same test number (T3) at $R_{z}=1.6 \mathrm{~mm}$ but for the feed cutting force was also increased from a point $1=153.311 \mathrm{~N}$ to point $2=180.802 \mathrm{~N}$. Therefore, this will affect positively on the surface roughness, which is improving the quality and quantity of product.

Table 3. Test Results Measured From FEM While Various Nose Radiuses $\left(R_{z}-\mathrm{mm}\right)$.

\begin{tabular}{ccccccc}
\hline \multirow{2}{*}{$\begin{array}{c}\text { Machining } \\
\text { tests } \\
\text { number }\end{array}$} & $\begin{array}{c}\text { Nose } \\
\text { radius } \\
\boldsymbol{R}_{z} \text {-mm }\end{array}$ & \multicolumn{3}{c}{$\begin{array}{c}\text { Cutting parameters were } \\
\text { remained constant } \boldsymbol{d}, \boldsymbol{f}, \boldsymbol{v}_{\boldsymbol{c}}\end{array}$} \\
\cline { 3 - 7 } & & $\begin{array}{c}\text { Main Cutting } \\
\text { Force }\left(F_{c}\right) \mathrm{N}\end{array}$ & $\begin{array}{c}\text { Feed Cutting } \\
\text { Force }\left(F_{t}\right) \mathrm{N}\end{array}$ \\
\hline $\mathrm{T} 1$ & 0.8 & $\mathbf{1 7 3 . 4 7 5}$ & 151.737 & 157.424 & $\mathbf{1 7 2 . 3 9 6}$ \\
$\mathrm{T} 2$ & 1.2 & $\mathbf{1 9 7 . 5 2 7}$ & 183.543 & $\mathbf{1 7 3 . 5 7 5}$ & 153.266 \\
$\mathrm{~T} 3$ & 1.6 & 176.753 & $\mathbf{1 7 7 . 7 2 3}$ & 153.311 & $\mathbf{1 8 0 . 8 0 2}$ \\
\hline
\end{tabular}

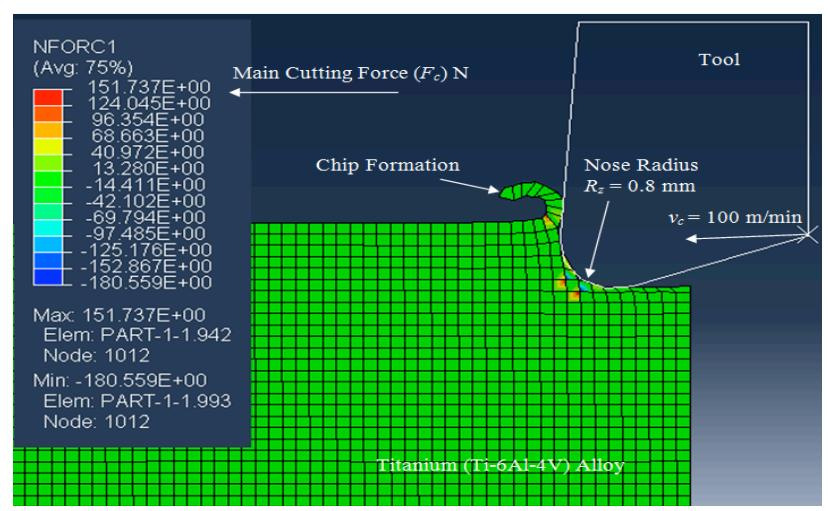

Fig. 3. Main Cutting Force Was Measured at T1 From Point 2.

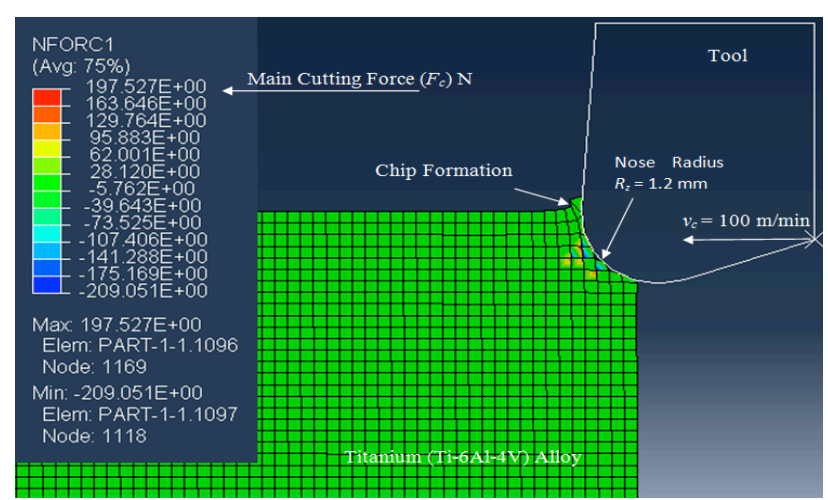

Fig. 4. Main Cutting Force Was Measured at T2 From Point 1.

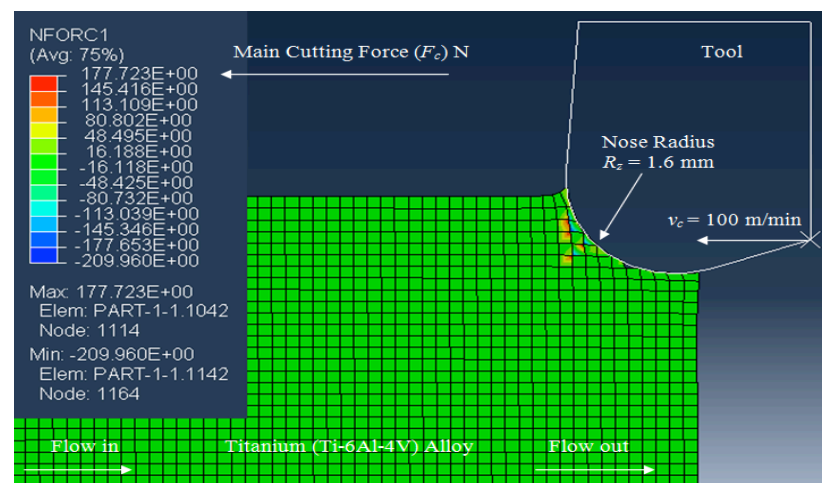

Fig. 5. Main Cutting Force Was Measured at T3 From Point 2.

\section{Conclusions}

From the obtained results, the conclusion can be drawn as follows:

An increase in the nose radius $\left(R_{z}-\mathrm{mm}\right)$ led to more convergence in terms of behavior between the main cutting force and feed cutting force during the machining of titanium (Ti-6Al-4V) alloy.

Convergence between the cutting force components in terms of their behavior on material, which is led to improving the quality and quantity of product.

The experiments were done by using finite-element modeling analysis when test the effect of nose radius $\left(R_{z}-\mathrm{mm}\right)$ on the cutting force components. This can contribute in reducing the cost of manufacturing in terms of prolongs the cutting tool life and machining time saving to improve the productivity.

\section{Acknowledgments}

The authors would like to acknowledge the support given by Universiti Tenaga Nasional in carrying out this research work. 
1. Xiaoping Yang and C. Richard Liu, MACHINING TITANIUM AND ITS ALLOYS, MACHINING SCIENCE AND TECHNOLOGY, 3(1), 107-139 (1999).

2. S. K. Bhaumik, C. Divakar, and A. K. Singh, "Machining Ti-6AI4V Alloy with a wBN-cBN Composite Tool," Materials \& Design, 16(4) (1995) 221-226.

3. A. R. Machado and J. Wallbank, "Machining of Titanium and Its Alloys-A Review," Proc Instn Mech Engrs, Part B: Journal of Engineering Manufacture, 204(1990) 53-60.

4. H. E. Trucks, "Machining Titanium Alloys," Machine and Tool BLUE BOOK, 82(I) (1987) 39-41.

5. Geoffrey Boothroyd, Winston A. Knight, Fundamentals of machining and machine tools, Third Edition 2005.

6. WU Hong-bing, Xu Chengguang, Jia Zhi-xin, Establishment of constitutive model of titanium alloy Ti6Al4V and validation of finite element, 2010 IEEE DOI 10.1109/ICMTMA.2010.555.

7. HKS Inc., USA ABAQUS/Standard User's Manual, Version 5.8, 1998.

8. Donald R. Lesuer, EXPERIMENTAL INVESTIGATIONS OF MATERIAL MODELS FOR Ti-6Al-4V TITANIUM AND 2024T3 ALUMINUM, U.S. Department of Transportation Federal Aviation Administration Final Report Office of Aviation Research Washington, DC 20591.

9. M.S. ElTobgy, E. Ng, M.A. Elbestawi, Finite element modeling of erosive wear, International Journal of Machine Tools \& Manufacture 45 (2005) 1337-1346.

10. T. Ozel, Y. Karpat, Identification of constitutive material model parameters for high strain rate metal cutting conditions using evolutionary computational algorithms, Mater. Manuf. Process. 22 (5-6) (2007) 659-667. 